\title{
Correction to: Stability analysis for a class of fractional-order nonlinear systems with time-varying delays
}

\section{Pourya Rahmanipour ${ }^{1} \cdot$ Hamid Ghadiri' (D)}

Published online: 26 September 2020

(C) Springer-Verlag GmbH Germany, part of Springer Nature 2020

\section{Correction to: Soft Computing}

https://doi.org/10.1007/s00500-020-05118-w

While typesetting the article all vertical lines were removed for all equations and it has been unnoticed in the further stages.
The original article has been corrected.

Publisher's Note Springer Nature remains neutral with regard to jurisdictional claims in published maps and institutional affiliations.

The original article can be found online at https:// doi.org/10.1007/s00500-020-05118-w.

$\square$ Hamid Ghadiri

h.ghadiri@qiau.ac.ir

Pourya Rahmanipour

rahmani.pourya@gmail.com

1 Faculty of Electrical, Biomedical and Mechatronics Engineering, Qazvin Branch, Islamic Azad University, Qazvin, Iran 